\title{
ANÁLISE DOS CONTEÚDOS DE HIDROGRAFIA NOS LIVROS DIDÁTICOS DO ENSINO MÉDIO DE GEOGRAFIA
}

\author{
Neianne Marinho ${ }^{\text {(a) }}$ Jamille Ramos ${ }^{(b)}$ Gustavo Barreto Franco ${ }^{(c)}$ \\ (a) Discentes do Curso de Licenciatura em Geografia, Universidade do Estado da Bahia, \\ neyanne_marinho@outlook.com \\ (b) Professor assistente do curso de Geografia, Universidade Estadual da Bahia, gustavopraia@ yahoo.com.br
}

\section{EIXO: GEOGRAFIA FÍSICA: CURRÍCULO, FORMAÇÃO E PRÁTICAS DE ENSINO}

\begin{abstract}
Resumo
O livro didático é a ferramenta didática mais utilizada nas escolas públicas atualmente, além de ser um instrumento para o professor, este serve como contribuição na formação do sujeito enquanto aluno e cidadão. Nesse sentindo, o presente trabalho buscou analisar os conteúdos de hidrografia nos livros de Geografia destinados ao ensino médio. Foram analisadas seis coleções de livros didáticos, todas contendo 3 volumes, onde foram averiguados conteúdos básicos da temática de Hidrografia. Para a concretização da pesquisa, foi feita uma revisão bibliografia, análise da formação dos autores, identificação da ordem dos conteúdos, abrangência, fundamentação da informação, situação dos conceitos, atualização, relação conteúdo/realidade e linguagem.
\end{abstract}

Palavras chave: Ensino de Geografia; Geografia Física; Livro Didático.

\section{Introdução}

O livro didático tem sido um dos recursos mais utilizados por professores como subsídio ao desenvolvimento das aulas, tanto para fonte de pesquisa dos alunos, assim como para determinação e delimitação dos conteúdos a serem trabalhados pelos professores no decorrer das unidades, pois representa um recurso de fácil acesso e disponibilidade para ambos.

A Hidrografia, para além da área da Geografia que estuda as águas e sua distribuição no Planeta, é um componente que também estabelece a condição cidadã das pessoas. Entende-se a importância dos temas/conceitos trabalhados em sala de aula, como recurso hídrico: poluição e proteção dos mananciais; ciclo hidrológico; e a importância das águas continentais e oceânicas. Por isso, a análise dos livros perpassa não só a existência ou não dos conteúdos, mas também, o papel que a escola tem quando o escolhe como apoio didático.

Nesse sentido, faz-se necessário uma escolha adequada do livro didático para que a aprendizagem tenha maior significância. Sendo assim, o presente trabalho tem como objetivo analisar os conteúdos de 
Hidrografia nos Livros didáticos de Geografia no Ensino Médio, a fim de compreender a sua veiculação nos livros.

\section{Metodologia}

Os procedimentos metodológicos que essa pesquisa perpassou foram: revisão bibliográfica; análise de coleções dos livros didáticos; e levantamento dos conteúdos de Hidrografia. As coleções analisadas por essa pesquisa foram: Fronteiras da Globalização (Coleção 1) - Editora Ática; Geografia - Espaço e Vivência (Coleção 2) - Editora Saraiva; Geografia - Sociedade e Cotidiano (Coleção 3) - Editora Escala Educacional; Geografia Geral e do Brasil (Coleção 4) - Editora Scipione; Ser Protagonista (Coleção 5) Organizadora Edições SM; Conexões Estudos de Geografia Geral e do Brasil (Coleção 6) - Editora Moderna. Após a definição dos temas básicos da Hidrografia a serem analisados, foram também identificados os seguintes aspectos: formação dos autores; ordenação dos conteúdos, áreas de abrangência, fundamentação da informação, situação dos conceitos, atualização dos temas, relação conteúdo/realidade, contextualização, linguagem dos conteúdos de geomorfologia e concordância com o(s) capítulo(s) no(s) qual(is) estão inseridos, assim como a presença de figuras e exercícios, procurando sempre estabelecer comparação com o enfoque estabelecido nos Parâmetros Curriculares Nacionais do Ensino Médio.

\section{Resultados e Discussão}

A tabela a seguir mostra os resultados quantitativos das análises. Sendo que, as coleções que apresentassem os conteúdos esperados, ganharam um 1,0 (um ponto), e as que não tivessem uma boa explicação dos conteúdos, 0,5 (meio ponto).

Analisando a tabela 1, é possível observar um esvaziamento de alguns conteúdos muito importante, como os tipos de Canais Fluviais e Águas Oceânicas. O último se destacando pelo fato das coleções 2, 3 e 5 não discorrerem sobre o assunto e, quando vistos, somente a 4 e $\mathbf{6}$ discorrendo com intensidade o assunto. Sobre os canais fluviais, apenas a coleção 5 apresentou uma boa explicação do conteúdo. O ciclo da água, distribuição e disponibilidade dos recursos, bacias hidrográficas do Brasil, por exemplo, estiveram presentes em todas as coleções. Ressalta-se a carência da presença de complementação dos textos, ilustrações e um aprofundamento da discussão. 
XVII Simpósio Brasileiro de Geografia Fisica Aplicada

I Congresso Nacional de Geografia Física
OS DESAFIOS DA GEOGRAFIA FÍSICA NA FRONTEIRA DO CONHECIMENTO

Instituto de Geociências - Unicamp

Campinas - SP

28 de Junho à 02 de Julho de 2017

Tabela 1: Análise da presença e qualidade da explicação dos conteúdos de Hidrografia com base nos valores estabelecidos.

\begin{tabular}{|l|c|c|c|c|c|c|}
\hline Conteúdos de Hidrografia: & $\begin{array}{c}\text { Coleção } \\
\mathbf{1}\end{array}$ & $\begin{array}{c}\text { Coleção } \\
\mathbf{2}\end{array}$ & $\begin{array}{c}\text { Coleção } \\
\mathbf{3}\end{array}$ & $\begin{array}{c}\text { Coleção } \\
\mathbf{4}\end{array}$ & $\begin{array}{c}\text { Coleção } \\
\mathbf{5}\end{array}$ & $\begin{array}{c}\text { Coleção } \\
\mathbf{6}\end{array}$ \\
\hline O ciclo da água & & & & & & \\
\hline Presença: & 1,0 & 1,0 & 1,0 & 1,0 & 1,0 & 1,0 \\
\hline Qualidade da explicação: & 1,0 & 0,5 & 0,5 & 1,0 & 0,5 & 1,0 \\
\hline $\begin{array}{l}\text { Distribuição e disponibilidade da } \\
\text { água }\end{array}$ & & & & & & \\
\hline Presença & 1,0 & 1,0 & 1,0 & 1,0 & 1,0 & 1,0 \\
\hline Qualidade da explicação: & 1,0 & 1,0 & 0,5 & 0,5 & 1,0 & 1,0 \\
\hline Bacias Hidrográficas & & & & & & \\
\hline Presença: & 1,0 & 1,0 & 1,0 & 1,0 & 1,0 & 1,0 \\
\hline Qualidade da explicação: & 0,5 & 0,5 & 0,5 & 0,5 & 1,0 & 0,5 \\
\hline Canais fluviais & & & & & & \\
\hline Presença: & 1,0 & 1,0 & 0 & 1,0 & 1,0 & 0 \\
\hline Qualidade da explicação: & 0,5 & 0,5 & 0 & 0,5 & 1,0 & 0 \\
\hline Hidrografia do Brasil & & & & & & \\
\hline Presença: & 1,0 & 1,0 & 1,0 & 1,0 & 1,0 & 1,0 \\
\hline Qualidade da explicação: & 0,5 & 0,5 & 1,0 & 0,5 & 0,5 & 0,5 \\
\hline Recursos Hídricos & & & & & & \\
\hline Presença: & 1,0 & 1,0 & 1,0 & 1,0 & 1,0 & 1,0 \\
\hline Qualidade da explicação: & 0,5 & 0,5 & 0,5 & 0,5 & 0,5 & 1,0 \\
\hline Águas Subterrâneas & & & & & & \\
\hline Presença: & 1,0 & 1,0 & 0 & 1,0 & 1,0 & 0 \\
\hline Qualidade da explicação: & 0,5 & 0,5 & 0 & 0,5 & 0,5 & 0 \\
\hline Águas Oceânicas & & & & & & \\
\hline Presença: & 1,0 & 0 & 0 & 1,0 & 0 & 1,0 \\
\hline Qualidade da explicação: & 0,5 & 0 & 0 & 1,0 & 0 & 1,0 \\
\hline Impactos sócio-ambientais & & & & & & \\
\hline Presença: & 1,0 & 1,0 & 1,0 & 1,0 & 1,0 & 1,0 \\
\hline Qualidade da explicação: & 0,5 & 0,5 & 1,0 & 1,0 & 1,0 \\
\hline
\end{tabular}

Por conseguinte, apenas as coleções 1 e $\mathbf{4}$ apresentaram todos os conteúdos esperados, mesmo que não trazendo uma boa explicação dos conceitos. Uma questão a destacar, e que foi compatível em quatro coleções analisadas, diz respeito análise mais crítica/social sobre os diferentes usos da água no mundo e contextualizada com o Brasil, abarcando, inclusive, as políticas dos recursos hídricos do país.

Outro ponto a salientar, é a situação dos conteúdos distribuídos nas coleções. Muitas delas não intercalaram os conteúdos a fim de estabelecer uma semelhança entre alguns processos da Hidrografia que estabelece relação direta com os conteúdos de Geomorfologia, Pedologia, Climatologia etc. 


\section{Considerações Finais}

O diagnóstico das coleções possibilitou caracterizar alguns elementos que descaracterizam e separam a Geografia Física da Geografia Humana nos conteúdos de Hidrografia, principalmente no âmbito da educação escolar. Por fim, sugere-se que os autores de livros didáticos de geografia tenham mais atenção com a distribuição dos conteúdos de Hidrografia nos livros didáticos, adequando os conteúdos a cada série, seguindo o sugerido pela Matriz de referência para o Ensino Médio e, que procurem sempre apresentar ilustrações, pois estas também podem servir como fonte de pesquisa pra os alunos. Sendo necessária ainda, a busca por uma maior articulação entre os conteúdos e os acontecimentos cotidianos que são estudados. As análises de livros didáticos contribuem para produções de materiais mais elaborados e aprimorados, a meta a ser alcançada para que se tenham livro com menos deficiências e de maior confiabilidade.

\section{REFERÊNCIAS}

ALBUQUERQUE, M. A. M. de; BIGOTTO, J. F; VITIELLO, M. A. Geografia sociedade e cotidiano. 3.ed. São Paulo: Escala Educacional, 2013.

ALMEIDA, L. M . A. de; RIGOLIN, T. B. Fronteiras da Globalização. 2. ed. São Paulo: Editora Àtica, 2014.

ARAÚJO, L. T. R; GUIMARÃES, R. B. Conexões: estudos de Geografia Geral e do Brasil. 2. ed. São Paulo: Editora Moderna, 2013.

BOLIGIAN, A. T. A; BOLIGIAN. L. Geografia - Espaço e Vivência. 1. ed. São Paulo: Saraiva, 2010.

BRASIL, Secretaria de Educação Média e Tecnológica. Parâmetros curriculares nacionais: ensino médio. Brasília: MEC; SEMTEC, 2002.

MOREIRA, J. C; SENE, E. de. Geografia Geral e do Brasil: espaço geográfico e globalização. 2. ed. São Paulo: Scipione, 2013.

MOREIRÃO, F. B. Ser protagonista: Geografia. 2. ed. São Paulo: Edições SM, 20

PLANO NACIONAL DO LIVRO DIDÁTICO PARA O ENSINO MÉDIO- PNLEM. Guia do livro didático. FNDE: Brasília, 2015. 